\title{
A EXPANSÃO DA IRRIGAÇÃO POR PIVÔS CENTRAIS NO ESTADO DE GOIÁS (1984-2015)
}

\author{
EXPANSION OF CENTER-PIVOT IRRIGATION IN \\ THE STATE OF GOIÁS(1984-2015)
}

\author{
LA EXPANSIÓN DEL RIEGO MEDIANTE PIVOTES BASES \\ CENTRALES EN EL ESTADO DE GOIÁS (1984-2015)
}

Lindolfo Caetano Pereira Júnior - Universidade Federal de Goiás - Goiânia - Goiás - Brasil
lindolfocaetano@gmail.com

Nilson Clementino Ferreira - Universidade Federal de Goiás - Goiânia - Goiás - Brasil

nclferreira@gmail.com

Fausto Miziara - Universidade Federal de Goiás - Goiânia - Goiás - Brasil

faustomiziara@uol.com.br

\begin{abstract}
Resumo
Neste artigo, 0 avanço da irrigação por pivôs centrais em Goiás é analisado em um contexto de expansão da fronteira agrícola. Tal abordagem visou verificar se o trinômio relevo, pedologia e infraestrutura, guias da ocupação agrícola no estado, também é agente do avanço da irrigação. Para tal, foram utilizados dados governamentais e imagens Landsat para o mapeamento desses equipamentos no período de 1984 a 2015. No ano de 2015, o estado apresentou um total de 3.489 equipamentos, perfazendo uma área irrigada de 242.128 ha. Observou-se um claro padrão de distribuição da irrigação por pivôs no estado, sendo que $60 \%$ dos equipamentos existentes encontram-se em área de relevo plano com latossolos e até 10 quilômetros de uma rodovia pavimentada. Essa técnica está consolidada em Goiás e tende a se expandir nos próximos anos, em uma expansão gradual e contínua, fatos que facilitam as ações de gestão dos recursos hídricos em longo prazo. Os equipamentos mapeados encontram-se em áreas de preço médio da terra, mais afastadas dos grandes centros, mas com a infraestrutura necessária para o escoamento da produção.
\end{abstract}

Palavras-chave: Fronteira agrícola, irrigação, recursos hídricos, infraestrutura.

\section{Abstract}

In this paper the Goiás advance of center-pivot irrigation is analyzed in the context of expansion of the agricultural frontier. This approach aimed to verify the influence of the triad: terrain, soil, and infrastructure, which guide the state's agricultural frontier, on the expansion of center-pivot irrigation in Goiás. For this purpose, we used Government data and Landsat images for mapping such equipment from 1984 to 2015. The state had a total of 3,489 facilities covering an irrigated area of 242,128 hectares in 2015. There was a clear pattern of distribution of irrigation pivots within the state, $60 \%$ of existing equipment is located on flat relief terrain with latosols and as close as 10 kilometers of a paved highway. This technique is consolidated in Goiás and tends to expand in the coming years, being a gradual and continuous expansion that facilitates long-term water resource management action. The mapped equipment is located in mid-priced land areas, more distant from the major urban centers, however with the required infrastructure for the production distribution.

Keywords: Agricultural frontier, irrigation, water resources, infrastructure. 
Resumen

En este estudio se analizó el avance del riego por pivotes centrales en Goiás, en el contexto de expansión de la frontera agrícola. Este enfoque tuvo como objetivo verificar la influencia del trinomio: relieve, suelo e infraestructura, que eran las guías de la frontera agrícola del estado, en cuanto a la expansión del riego por pivotes centrales en Goiás. Para ello se utilizaron datos gubernamentales e imágenes Landsat para cartografiar estos equipos en el periodo de 1984 a 2015. En el año 2015, el estado contabilizó un total de 3.489 equipos, sumando 242,128 hectáreas de riego. Se observó un patrón claro relacionado a la distribución del riego por pivotes en el estado, siendo que el $60 \%$ de los equipos existentes en áreas de relieve plano con latosuelos y hasta 10 kilómetros de una carretera asfaltada. Está técnica se encuentra consolidada en Goiás, se extenderá en los años venideros y está en expansión gradual y continuada, hecho que facilita la gestión de los recursos hídricos a largo plazo. Los equipos cartografiados están ubicados en zonas donde las superficies tienen un precio medio, están más alejadas de los grandes centros, pero tienen la infraestructura necesaria para darle salida a la producción.

Palabras clave: Frontera agrícola, irrigación, recursos hídricos, infraestructura.

Introdução

As alterações mais importantes que as sociedades humanas têm promovido no ambiente global são oriundas da agropecuária associada aos expressivos avanços científicos e tecnológicos das últimas décadas (Matson, 1997). Essas alterações vêm causando impactos negativos, mas, por outro lado, têm sido suporte ao crescimento da população global por prover alimentos e outros produtos à base de biomassa (Barretto et al., 2013).

A irrigação se apresenta como um fator-chave nesse processo, por ter possibilitado um salto de produtividade no mundo nas últimas décadas, ocupando cerca de $20 \%$ da área arável e sendo responsável por $47 \%$ da produção global (FAO, 2011). Trata-se de uma atividade que está em processo de expansão, devendo crescer 20\% (40 milhões ha) até 2030, especialmente nos países em desenvolvimento (Darko et al., 2016).

Não obstante, esse aumento da irrigação e a intensificação agrícola trazem consequências que podem ser problemáticas, tanto para o próprio setor quanto para a sociedade em geral. Em nível local, erosão, perda de solos, poluição, salinização e eutrofização de rios e lagos são os principais problemas; já em nível global, há impactos na atmosfera continental e no clima (Matson, 1997). Tais consequências levam indubitavelmente a um declínio das reservas hídricas em muitas partes do mundo, fato que não representa apenas um grande interesse científico, mas, sobretudo, uma preocupação social (Taylor, 2014).

Dessa forma, a gestão hídrica passa obrigatoriamente pelo entendimento das dinâmicas de consumo locais, seja para irrigação, seja para consumo humano ou outros. Existe a profunda necessidade de 
previsão da expansão ou retração do consumo hídrico. Isto posto, neste artigo procura-se entender o processo de ocupação do território goiano pela irrigação por pivôs centrais, processo iniciado nos idos de 1984 e que tem se expandido de forma sólida no estado.

A perspectiva a ser adotada para a compreensão desse processo será que o uso da irrigação representa uma forma (dentre outras) de intensificação da agropecuária, por meio de maiores investimentos. Portanto, o avanço da irrigação no estado será analisado em um contexto mais amplo de expansão da fronteira agrícola.

\section{A fronteira agrícola no estado de Goiás}

Goiás está situado na região Centro-Oeste do Brasil. Cerca de 97\% de seu território é ocupado pelo bioma Cerrado e os demais 3\% são ocupados por formações de mata atlântica, pouco preservadas, situadas na região sul (Machado et al., 2007). O estado possui enorme riqueza de recursos hídricos, sendo berço de três grandes bacias hidrográficas nacionais: Tocantins, Paraná e São Francisco (Eiten, 1993; Nascimento, 1991; Teixeira Neto, 2009).

O bioma Cerrado apresenta como importante característica o clima, sendo a precipitação a variável climática mais notável devido ao comportamento sazonal, com um longo período de estiagem - abril até outubro - e um longo período de chuvas - novembro a março (Cardoso, Marcuzzo e Barros, 2014; Marcuzzo, Faria e Pinto Filho, 2012; Silva et al., 1998). A precipitação média anual fica entre 1.200 e 1.800 mm (Marcuzzo, Faria e Pinto Filho, 2012).

Nos meses de seca mais severa, em julho e agosto, as taxas de precipitação chegam a $0 \mathrm{~mm}$, contra $355 \mathrm{~mm}$ médios no mês de dezembro (INMET, 1992). Além disso, Silva et al. (1998) demonstram que o excesso hídrico climático apresenta uma distribuição espacial heterogênea no estado, ao passo que o déficit hídrico exibe um comportamento homogêneo.

Neste contexto, o clima, associado à baixa fertilidade natural dos solos do Cerrado, foi, até meados da década de 1970, o principal obstáculo à produção intensiva em Goiás. A partir daí, inicia-se um processo que pode ser denominado de expansão da fronteira agrícola, apoiado fortemente na modernização, que resultou na evolução dos sistemas de manejo e irrigação, viabilizando a produção em larga escala no território goiano (Miziara e Ferreira, 2008; Silva et al., 2013). 
Por outro lado, apesar de no século XX ter ocorrido uma importante expansão das atividades industriais no país, principalmente na região Sudeste, o estado de Goiás atuou como parte desse processo, intensificando a produção de matérias-primas. Assim, a ocupação de novas áreas na fronteira e a redução dos custos de produção tornaram-se a base do crescimento da produção agropecuária goiana (Bezerra e Cleps Jr., 2004).

A localização mais afastada dos grandes centros consumidores da região Sudeste força uma redução do valor agregado da terra em Goiás (Rezende, 2002). Esse valor é também fortemente influenciado pelas condições naturais (fertilidade e relevo) e pela tecnologia, que levou a produção agrícola no Cerrado a um novo patamar (Arissane, 2006; Ferreira, Miziara e Ribeiro, 2008; Inocêncio e Calaça, 2009; Miziara e Ferreira, 2008; Prado, Miziara e Ferreira, 2012; Rezende, 2002; Rodrigues e Miziara, 2008; Silva e Miziara, 2011). As técnicas de correção de solo, associadas ao melhoramento genético dos cultivares, sobretudo soja e trigo, permitiram um salto na produção agrícola da região, consolidando o agronegócio e colocando Goiás entre os principais exportadores de grãos do Brasil (IMB, 2015). Dentre as principais tecnologias empregadas, os pivôs centrais foram um dos meios de vencer a última barreira existente no Cerrado para a produção agrícola superintensiva: a chuva.

Dessa forma, o avanço desse tipo de irrigação está inserido em um processo maior, de expansão da fronteira agrícola, ocorrido em Goiás. Neste caso, norteado por programas governamentais, tais como o Programa de Cooperação Nipo-Brasileira para o Desenvolvimento dos Cerrados (PRODECER), cuja principal função foi tornar o Cerrado uma área produtora de grãos, sobretudo soja, produto deficitário no mercado japonês (Inocêncio e Calaça, 2009). Por conseguinte, neste artigo, a irrigação por pivôs centrais é tratada como um evento inserido nesse processo de fronteira agrícola.

\section{Metodologia}

Este estudo compreende o período entre 1984 e 2015, tendo sido analisados os anos de 1984, 1990, 1996, 2000, 2003, 2006, 2012, 2013 e 2015. Para a obtenção das áreas irrigadas por pivôs centrais, foram levantados junto ao Sistema Estadual de Geoinformação de Goiás (SIEG) os mapeamentos realizados para os anos de 2000, 2003, 2006, 2012 e 2013. Esses dados são resultado de um conjunto de ações de mapeamento realizadas no âmbito do 
estado de Goiás por diversas secretarias. Para complementar a série histórica necessária, os anos de 1984, 1990 e 1996 foram mapeados a partir de imagens Landsat5 - TM (Thematic Mapper) e, para o ano de 2015, foram utilizadas imagens Landsat8 - OLI (Operational Land Imager).

Essas imagens foram processadas utilizando-se a biblioteca Geospatial Data Abstraction Library (GDAL), com o fim de gerar as composições necessárias à obtenção, por interpretação visual, dos pivôs centrais. Foram utilizados todos os dados disponíveis entre os meses de abril e outubro dos respectivos anos, perfazendo um total de 513 imagens. A utilização de várias cenas do mesmo ano justifica-se pela heterogeneidade de utilização desses equipamentos ao longo do tempo, fato que pode levar à não identificação dessas áreas, ao se usar apenas uma data como referência.

Após a obtenção das áreas irrigadas por pivôs centrais, realizou-se o cruzamento destas com dados de declividade, a qual foi obtida a partir de imagens SRTM (Shuttle Radar Topography Mission) com resolução espacial de 30 metros, processadas em ambiente de Sistema de Informações Geográficas (SIG) para extração da declividade no estado.

Os dados de irrigação também foram cruzados com os de pedologia, obtidos junto ao SIEG. Além disso, foi analisada a relação entre o sistema rodoviário existente em Goiás e essas áreas com pivôs centrais, com o objetivo de melhor caracterizar a influência da infraestrutura de transportes sobre a localização espacial desses equipamentos.

Os resultados foram ainda estudados sob a ótica da divisão territorial de gestão hídrica, ou seja, do recorte espacial utilizado para a gestão de recursos hídricos no estado de Goiás. Tais dados foram obtidos junto à Secretaria de Meio Ambiente e Recursos Hídricos, Infraestrutura, Cidades e Assuntos Metropolitanos de Goiás (SECIMA).

Esse conjunto de ações e variáveis nos permitiu traçar um perfil da ocupação do estado de Goiás pela irrigação por pivôs centrais, possibilitando-nos compreender a dinâmica espaçotemporal desse processo e quais as implicações futuras dessa ocupação, sobretudo, para os recursos hídricos.

\section{Resultados e discussões}

A utilização de pivôs centrais para a irrigação em Goiás é um processo iniciado na primeira parte da década de 1980. Em 1984, o estado 
contava com apenas 10 (dez) equipamentos instalados. Estes se distribuíam em seis municípios goianos: Uruaçu (4), Castelândia (2), Cristalina (1), Jataí (1), Porteirão (1) e Santo Antônio de Goiás (1).

Desde então, o estado vem passando por um processo de evolução da irrigação por pivôs centrais, que levou o território goiano a contar com 3.489 equipamentos instalados no ano de 2015, totalizando uma área irrigada de aproximadamente 242.127 ha. Esse processo, como pode ser observado na Figura 1, ocorreu de forma gradual, havendo um incremento da ordem de 9.600ha.ano ${ }^{-1}$ e 152 equipamentos.ano ${ }^{-1}$.

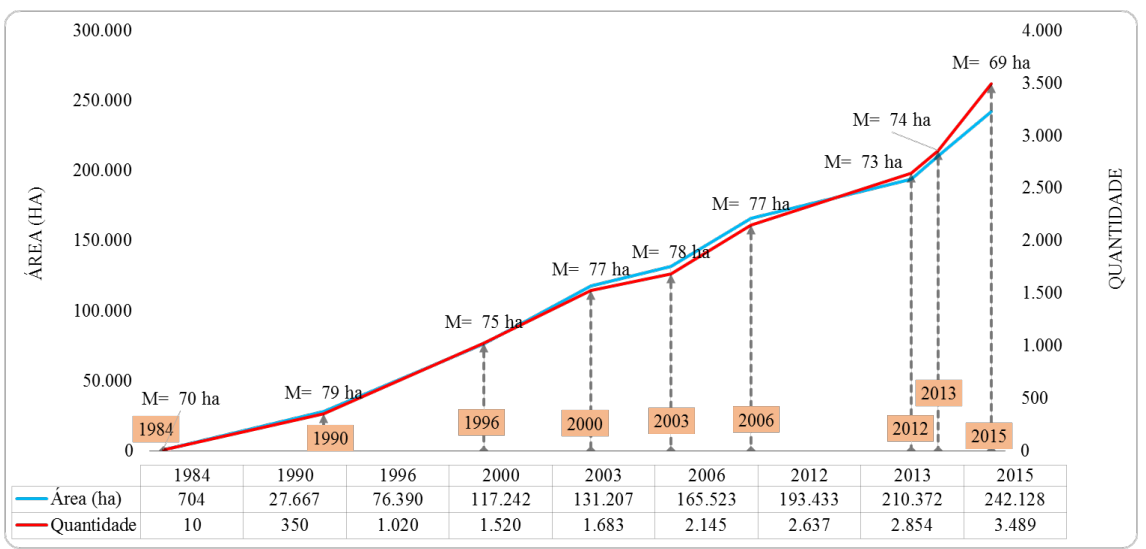

Figura 1 - Evolução da irrigação por pivôs centrais no estado de Goiás entre 1984-2013.

Fonte: Imagens Landsat, IMB. Elaborado pelos autores.

A área média dos equipamentos aqui existentes não tem se alterado significativamente nas últimas três décadas, mantendo-se por volta de 70 ha. Por outro lado, a partir do ano de 2012, houve uma queda na área média dos novos equipamentos, o que levou a uma redução, naquele ano, para a ordem de 57 hectares da área média dos novos equipamentos. No ano de 2013, houve uma recuperação. Em 2015, observou-se novamente uma queda na área média dos novos equipamentos, ficando esta por volta de 50 ha. Entretanto, esse comportamento foi diretamente influenciado pela utilização desse tipo de técnica para a irrigação de cana-de-açúcar no município de São Luiz do Norte, onde a área média é de 43 ha. No restante do estado, a área média se manteve, em 2015, por volta de 70 ha. O que pode explicar essa característica é a concepção do sistema de irrigação. 
Esses equipamentos foram primeiramente desenvolvidos nos Estados Unidos da América, onde a unidade convencional de terras é da ordem de 65 hectares (Splinter, 1976), logo, esses sistemas foram concebidos para irrigar áreas próximas a esta, o que lhes confere bom custo-benefício.

Observa-se que, no período compreendido entre 1986 e 2015, a variação nos preços das commodities no mundo foi significativa, com uma elevação da ordem de $186 \%$ no preço da soja, de $206 \%$ no preço do milho e de $245 \%$ no preço do sorgo, que são algumas das principais culturas agrícolas de Goiás (Index Mundi, 2016). Além disso, no período entre janeiro de 1991 e abril de 2016, ocorreu um incremento da ordem de 38\% $(2005=100)$ no chamado Commodity FoodPrice Index, que inclui cereais, óleos vegetais, carnes, frutos do mar, açúcar, bananas e laranja (Index Mundi, 2016). Tais características notoriamente influenciaram a expansão da irrigação em Goiás, norteada fortemente pelos mercados externos.

No ano de 2015, dos 246 municípios goianos, 151 possuíam algum equipamento do tipo pivô central. Além disso, na série histórica 1984-2015, outros 16 municípios apresentaram, em algum momento, esse tipo de técnica de irrigação. O principal município, no que tange à irrigação por pivôs centrais em Goiás, é Cristalina, situada na região do entorno do Distrito Federal. O município possuía em 2015 um total de 718 equipamentos, perfazendo uma área de 57.098 ha, ou seja, cerca de $24 \%$ de toda a área que utiliza esse tipo de irrigação no estado. Não obstante, o município lidera nesse quesito desde 1990, além disso, em número de equipamentos, apresenta mais de quatro vezes a quantidade existente no município de Morrinhos, que conta com 160 pivôs, sendo o segundo com maior número. O município de Jussara, no oeste goiano, desponta como segundo com maior área irrigada por pivôs centrais, tendo aproximadamente 12.473 ha, ultrapassando Morrinhos, que tem a segunda maior quantidade de equipamentos, mas conta com uma área irrigada de 8.013 ha.

A distribuição espacial do processo de expansão da irrigação por pivôs centrais em Goiás pode ser dividida em dois grandes ciclos. $\mathrm{O}$ primeiro, que compreende até 1996, pode ser visto como parte de um processo de expansão da fronteira agrícola no território goiano (Miziara e Ferreira, 2008). Nesse período, a expansão se deu de forma mais esparsa, tendo-se a apropriação de novos territórios, aqui representados pelos municípios. A partir do ano de 1996, iniciou-se uma segunda fase, ocorrendo um processo de densificação das áreas irrigadas no interior dos municípios, ou seja, começam a ser instalados novos equipamentos 
próximos a equipamentos já existentes. Comportamento semelhante foi observado por Barretto et al. (2013), ao identificarem um padrão de expansão agrícola e de concentração ocorrendo dentro de pequenas distâncias umas das outras.

Tal característica de expansão pode ser observada na matriz de correlação, presente na Figura 2, a qual evidencia que até 1996 não havia uma correlação realmente significativa entre a quantidade de equipamentos existentes no estado, naquele ano por município, e os demais anos. Por outro lado, após os anos 2000, a correlação com os anos subsequentes passa a ser expressiva, sendo alta inclusive entre 2000 e 2015, período no qual temos uma correlação de 0,968.

\begin{tabular}{c|cc|c|cccccc} 
& $\mathbf{1 9 8 4}$ & $\mathbf{1 9 9 0}$ & $\mathbf{1 9 9 6}$ & $\mathbf{2 0 0 0}$ & $\mathbf{2 0 0 3}$ & $\mathbf{2 0 0 6}$ & $\mathbf{2 0 1 2}$ & $\mathbf{2 0 1 3}$ & $\mathbf{2 0 1 5}$ \\
\hline $\mathbf{1 9 8 4}$ & $\mathbf{1}$ & 0,131 & 0,121 & 0,159 & 0,176 & 0,168 & 0,162 & 0,164 & 0,163 \\
$\mathbf{1 9 9 0}$ & 0,131 & $\mathbf{1}$ & $\mathbf{0 , 8 5 1}$ & 0,710 & 0,699 & 0,666 & 0,658 & 0,667 & 0,673 \\
$\mathbf{1 9 9 6}$ & 0,121 & 0,851 & $\mathbf{1}$ & 0,902 & 0,885 & 0,859 & 0,852 & 0,854 & 0,853 \\
$\mathbf{2 0 0 0}$ & 0,159 & 0,710 & 0,902 & $\mathbf{1}$ & 0,990 & 0,981 & 0,976 & 0,978 & 0,968 \\
$\mathbf{2 0 0 3}$ & 0,176 & 0,699 & 0,885 & 0,990 & $\mathbf{1}$ & 0,995 & 0,991 & 0,992 & 0,983 \\
$\mathbf{2 0 0 6}$ & 0,168 & 0,666 & 0,859 & 0,981 & 0,995 & 1 & 0,997 & 0,997 & 0,988 \\
$\mathbf{2 0 1 2}$ & 0,162 & 0,658 & 0,852 & 0,976 & 0,991 & 0,997 & 1 & 0,999 & 0,990 \\
$\mathbf{2 0 1 3}$ & 0,164 & 0,667 & 0,854 & 0,978 & 0,992 & 0,997 & 0,999 & $\mathbf{1}$ & 0,992 \\
$\mathbf{2 0 1 5}$ & 0,163 & 0,673 & 0,853 & 0,968 & 0,983 & 0,988 & 0,990 & 0,992 & $\mathbf{1}$
\end{tabular}

Figura 2- Matriz de correlação entre os anos e a quantidade de pivôs centrais por município, que evidencia uma mudança no comportamento da correlação entre os anos após 1996. Tal fato revela uma mudança de tendência na expansão da irrigação por pivôs centrais, passando a ser mais concentrada próxima a equipamentos já existentes.

Fonte: Elaborado pelos autores.

No que tange ao processo de fronteira agrícola em Goiás, Miziara e Ferreira (2008) o dividem em 5 (cinco) momentos, agrupados em três grandes fases: Frente de Expansão, Frente Pioneira e Fronteira Agrícola (Figura 3). Essa última fase é enquadrada pelos autores dentro do conceito de Renda Diferencial I. Porém, observa-se que no início (1984), e com maior ênfase a partir de 1996, inicia-se um processo de intensificação no uso do solo já cultivado, o que representa uma mudança no perfil produtivo e um avanço no sentido da Renda Diferencial II (Figura 3). 


\begin{tabular}{|l|l|}
\hline $\begin{array}{c}\text { Frente de expansão } \\
\text { Ocupação } \\
\text { pelo ouro }\end{array}$ & $\sum 1801$ \\
& $\begin{array}{c}\text { Ocupação do } \\
\text { Sul pelos } \\
\text { "Geralistas" }\end{array}$ \\
\hline
\end{tabular}
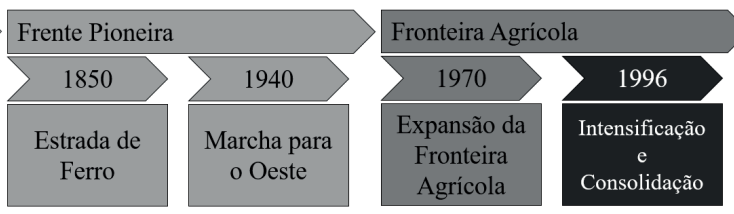

Figura 3 - Fluxo de expansão de fronteiras no território goiano, destacando o processo aqui identificado de intensificação e consolidação, identificado a partido do ano de 1996.

Fonte: Adaptado de Miziara e Ferreira, 2008.

Assim como os demais processos de expansão da fronteira agrícola em Goiás, a exemplo da expansão da cana-de-açúcar (Silva e Miziara, 2011) e da pecuária (Rodrigues e Miziara, 2008), esse processo é marcado por uma grande concentração no centro-sul do estado (Figura 4). Já em 2015, é possível observar um avanço importante da irrigação por pivôs centrais para o norte do estado, atingindo principalmente o norte do Distrito Federal e os municípios às margens do rio Araguaia, já no oeste de Goiás.

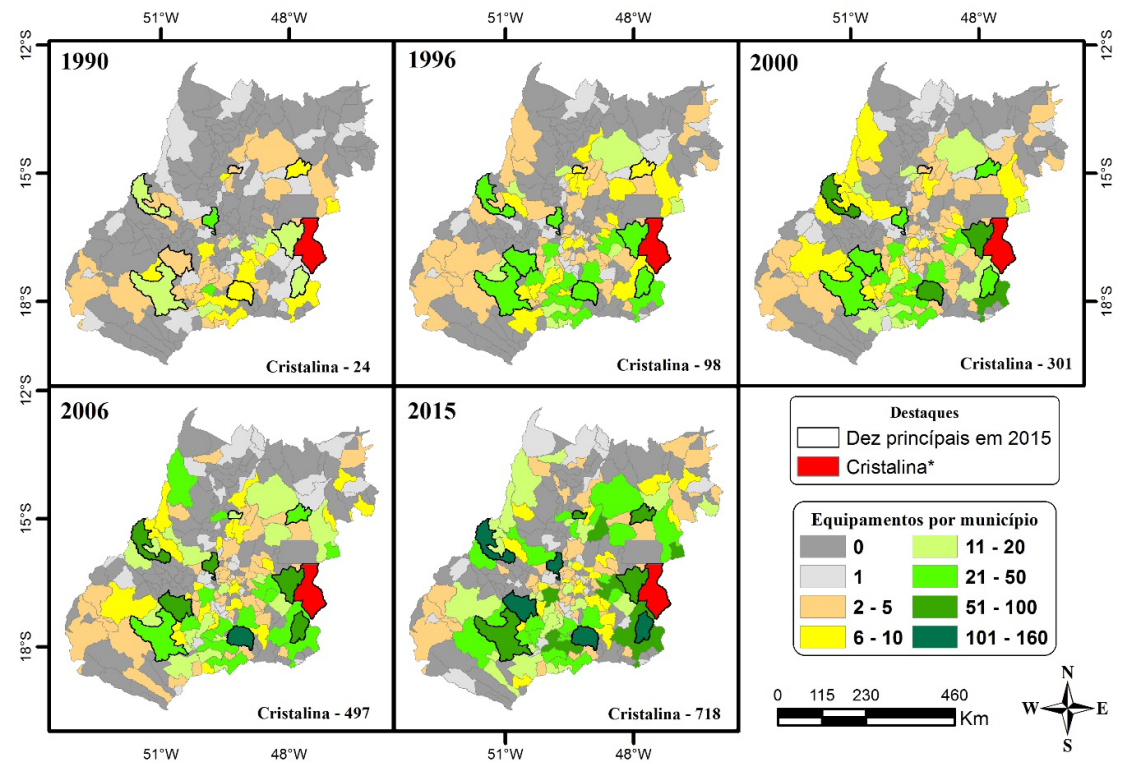

Figura 4 - Mapa da evolução da irrigação por município no estado de Goiás, nos anos de 1990, 1996, 2000, 2006 e 2015, com destaque para os dez principais em 2015. 
Outro aspecto ligado à distribuição espacial desses equipamentos é o preço da terra. Ferreira, Miziara e Ribeiro (2008) demonstram, por meio da análise do preço da terra no estado de Goiás, que a antropização privilegia as áreas com melhores condições de geração de renda, uma vez que o preço expressa justamente essa capacidade. Neste sentido, nota-se que a ocupação por pivôs centrais se concentra nas áreas com um preço da terra mediano, mais afastadas da região metropolitana de Goiânia e próximas a infraestruturas essenciais. Tal fato é facilmente explicado pelos investimentos necessários para viabilizar a irrigação, que elevam o custo inicial de produção. Dessa forma, observa-se que há um balanceamento entre o custo da terra e os investimentos em irrigação. Nos termos do modelo teórico apresentado acima, tem-se um compromisso entre as características naturais do solo (Renda Diferencial I) e a intensificação da tecnologia por meio de maiores investimentos (Renda Diferencial II).

Esses resultados evidenciam uma taxa de expansão progressiva e constante da agricultura irrigada em Goiás nas últimas três décadas, em um ritmo gradual e em primeira análise de forma bastante sustentável, pois resistiu a duas crises hídricas importantes no país, em 2002 e 2014, além de diferentes panoramas econômicos pelos quais o Brasil tem passado nas últimas quatro décadas. Nesse intervalo, ocorreram movimentos econômicos importantes, tais como mudança de moeda, o abandono do regime de bandas cambiais em 1999 e a crise econômica mundial de 2008. Esses fatores não foram suficientes para modificar o fluxo de intensificação da produção agrícola no território goiano.

Isto posto, é possível afirmar que há uma alta viabilidade econômica para a expansão ainda mais acentuada dessas áreas no futuro, uma vez que trata-se de uma atividade fortemente ligada à demanda externa, que, segundo dados da Organização das Nações Unidas para Agricultura e Alimentação (FAO), deverá crescer para algo como 3 bilhões de toneladas diante dos 2,4 bilhões estimados para 2015/2016 (FAO, 2009, 2016). Associa-se a isto o fato de, no estado de Goiás, a água ainda ser um recurso sem custos de captação. Caso ocorra a cobrança pelo uso da água, conforme a legislação vigente (Lei no 9433, 1997), não deverá representar uma fonte de restrição ao setor agrícola. Dessa forma, o maior custo para a irrigação fica ligado à fonte de energia para bombeamento hídrico, que conta ainda com uma redução das tarifas, conforme legislação especifica (ANEEL, 2010). 
Evolução por região hidrográfica de gestão hídrica

Outro prisma para a análise desse processo de ocupação pela agricultura intensiva é por meio da divisão territorial de gestão hídrica (Figura 5). Não obstante, o maior impacto direto da intensificação desse tipo de técnica agrícola é sobre os recursos hídricos. Nesse ponto, o estado de Goiás se destaca por não ter autorizado, até o ano de 2015, a captação de águas subterrâneas para a irrigação por pivôs centrais, conforme dados obtidos junto à Secretaria de Meio Ambiente, Recursos Hídricos, Infraestrutura, Cidades e Assuntos Metropolitanos do Estado de Goiás (SECIMA-GO). É notório que esse tipo de fonte hídrica tem uma qualidade superior e um tempo de renovação que, por vezes, chega a séculos (Foster et al., 2006). Tais fatos tornam este um recurso mais vulnerável à sobreexplotação e à contaminação ou à poluição direta.

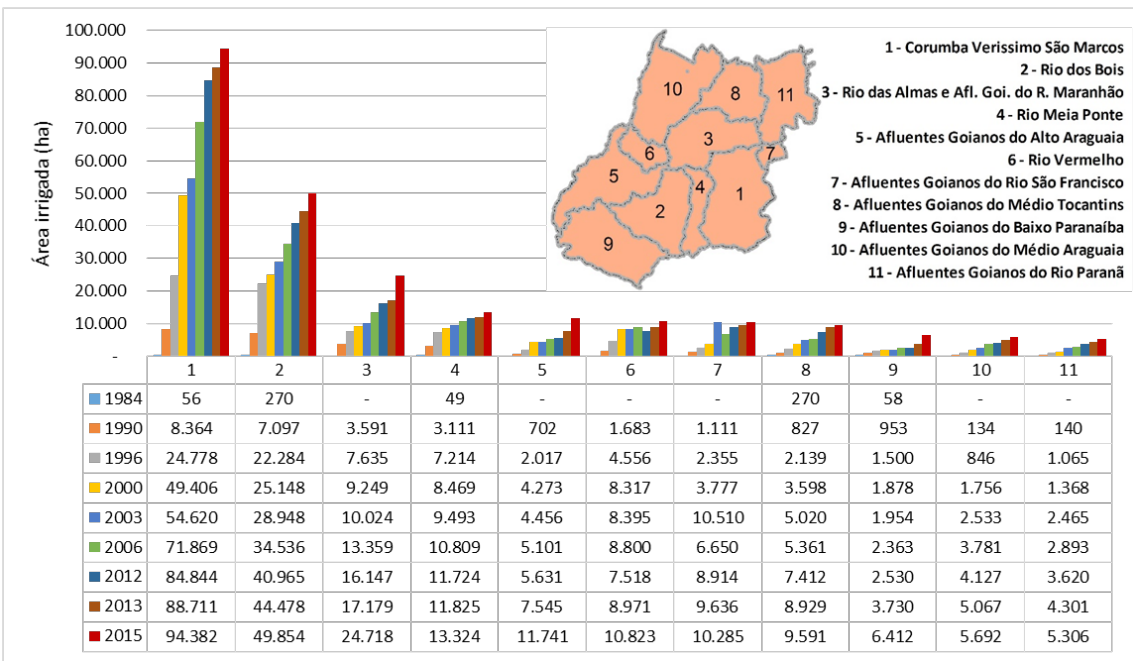

Figura 5 - Evolução da irrigação por pivôs centrais no estado de Goiás por comitês de bacia, série histórica 1984-2015, contendo o ranking dos comitês.

Fonte: Elaborado pelos autores.

Observa-se que, no início da série, as regiões do rio São Marcos/ Veríssimo e do rio dos Bois apresentavam áreas irrigadas praticamente equivalentes, sendo que a primeira exibia algo em torno de $10 \%$ a mais de área irrigada por pivôs centrais. Porém, no decorrer da série histórica, 
houve uma evolução bastante acentuada no rio São Marcos/Veríssimo e a bacia do Rio dos Bois teve uma evolução tímida. Nas demais regiões hidrográficas, também verificou-se um crescimento da área irrigada, porém em taxas muito menores que as duas regiões hidrográficas anteriormente citadas.

No período, ficou evidente a ascensão da irrigação por pivôs na área do comitê dos rios Corumbá, Veríssimo e da porção goiana do rio São Marcos. Não obstante, em levantamento realizado pela Agência Nacional de Águas (ANA; EMBRAPA, 2013), a bacia hidrográfica do rio São Marcos é a que tem o maior número de equipamentos de irrigação do tipo pivô central no Brasil. Essa região hidrográfica conta ainda com a presença de sete usinas hidrelétricas, sendo seis no estado de Goiás e uma no Distrito Federal, o que vem causando um aumento na demanda hídrica local. Sabe-se que a geração de energia não é um uso consultivo, porém, há uma "reserva" necessária ao perfeito funcionamento dessas usinas que compromete, ou limita, os usos, sobretudo, a montante. Lívia e Hora (2015) destacam o conflito existente na bacia do rio São Marcos, entre irrigantes, e a Usina Hidrelétrica de Batalha, que vem resultando em perdas energéticas entre $8 \%$ e 19\% na usina e causando certa instabilidade na região.

\section{Pedologia}

No que tange às características pedológicas, os pivôs centrais atualmente instalados em Goiás estão localizados majoritariamente sobre latossolos. A série histórica revela que em 1984 os dez equipamentos existentes estavam sobre esse tipo de solo e, a partir de 1990, em média 85\% da área irrigada por pivôs centrais encontra-se em latossolos.

O segundo tipo de solo predominante é o cambissolo, não ultrapassando em 2015 uma área de 20.000 hectares ou 7\% do total irrigado por pivôs centrais em Goiás. Observa-se que a maioria dos equipamentos se encontra instalada sobre latossolos, existindo apenas algumas áreas que são recobertas por tipos de solos menos manejáveis mecanicamente. Não obstante, a escala de mapeamento de solos pode ser considerada grosseira, o que leva a incertezas quanto à real composição existente nas áreas desses equipamentos, quando pequenas porções são compostas por outros tipos de solo. 


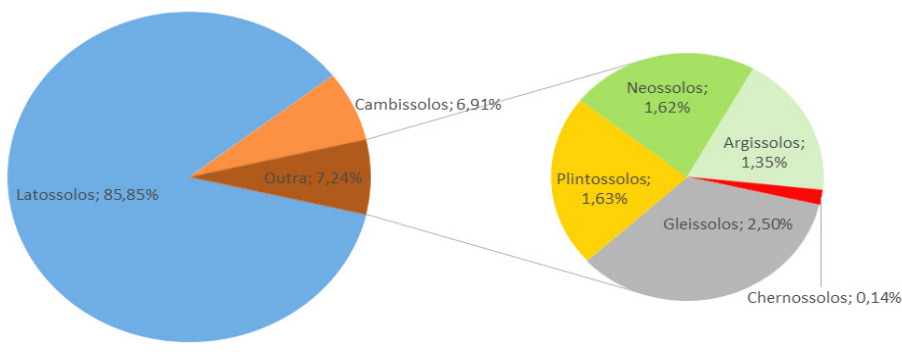

Figura 6 - Representação da pedologia dos pivôs centrais no estado de Goiás no ano de 2015.

Fonte: Elaborado pelos autores

Fica evidente, portanto, que, mesmo com o avanço tecnológico que tem possibilitado a correção dos solos do Cerrado, a mecanização ainda prevalece sobre os latossolos. Não obstante, essas áreas demandam menores custos em correção do solo, o que possibilita o investimento de forma mais acentuada em técnicas de irrigação mais robustas. Além disso, o retorno produtivo nessas áreas precisa acompanhar o desenvolvimento dos preços da terra no estado, ou seja, como essas áreas possuem maior valor agregado, a produção precisa ser mais rentável, uma vez que há uma notória pressão exercida pelos diversos setores produtivos por áreas de solos mais produtivos. Observa-se que, com o aumento do preço da terra, a mecanização torna-se indispensável para a obtenção de retorno dos investimentos na aquisição e na manutenção da terra.

\section{Declividade}

Goiás apresenta um relevo notoriamente plano a suave ondulado, que ocupa cerca de 75\% de sua área (Macedo, 2015). Consequentemente, há uma predominância dos equipamentos do tipo pivô central nessas áreas. No ano de 2015, 90\% dos equipamentos existentes ocupavam áreas com declividade de até $6 \%$ ou $2,7^{\circ}$ (Figura 7).

A declividade média onde estes estão instalados é de 4\%, com um desvio padrão da ordem de 2,4\%. Não obstante, tais áreas estão associadas a solos bem drenados (latossolos) e a um custo maior da terra. Observa-se 
que existe uma alta mecanização do processo produtivo e há, dessa forma, uma limitação de maquinário que impede a evolução desse tipo de técnica para locais com relevo mais movimentado. Nesse contexto, fica claro que, indo ao encontro do que foi exposto por Prado, Miziara e Ferreira (2012), o avanço agrícola ora controlado pelas características pedológicas passa agora a sofrer uma restrição mais ligada ao relevo do que propriamente ao solo.

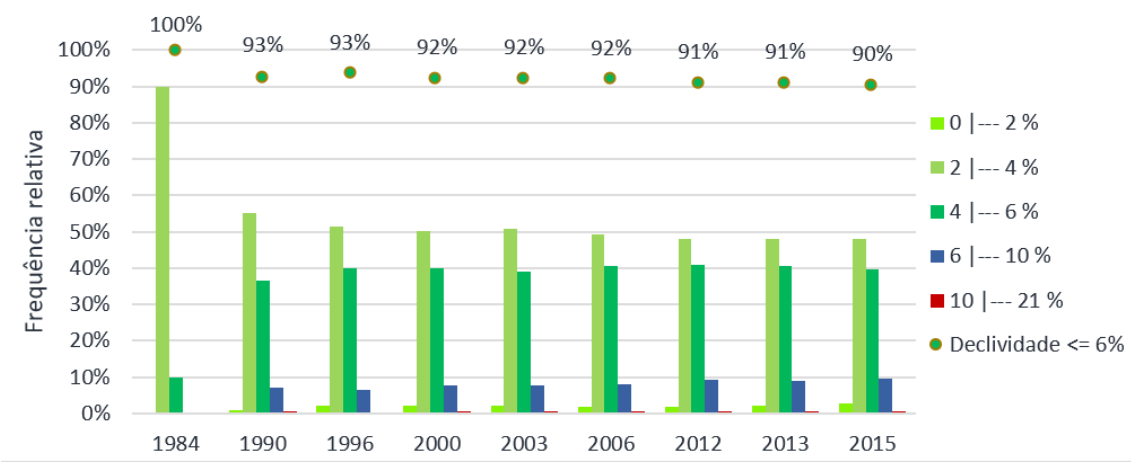

Figura 7 - Gráfico de frequência relativa da distribuição dos pivôs centrais em função da declividade.

Fonte: Elaborado pelos autores.

\section{Sistema rodoviário}

No tocante ao sistema rodoviário, há um padrão claro de distribuição dos equipamentos seguindo o sistema rodoviário pavimentado (rodovias federais e estaduais). Foi possível observar que 75\% dos equipamentos, ou seja, 2.625 deles encontram-se a até 10 quilômetros de uma rodovia pavimentada (Figura 8). Tal fato reforça o poder de indução do Estado no desenvolvimento regional.

Não obstante, o modal rodoviário é o mais importante para a produção agrícola em Goiás. Tal fato não desperta surpresa, uma vez que o Estado brasileiro tem adotado as rodovias como referência no país, em detrimento dos modais ferroviários e aquaviários. 


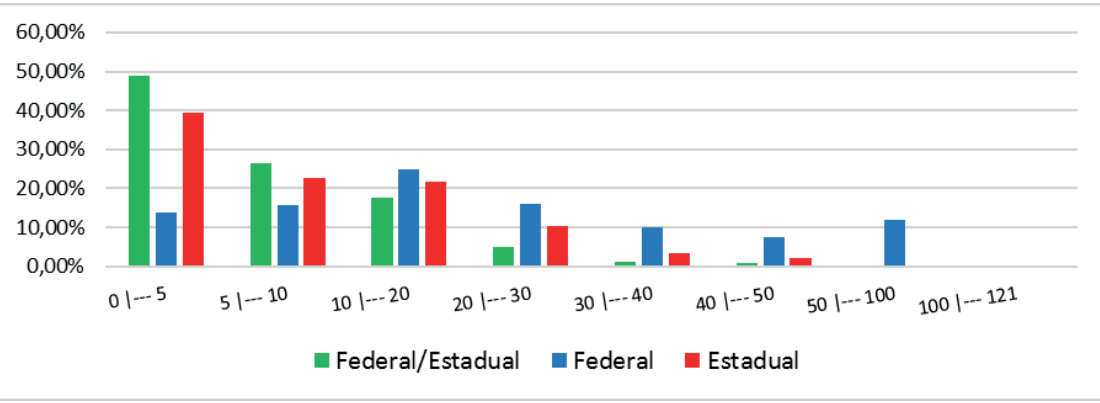

Figura 8- Gráfico da distribuição dos pivôs centrais em relação ao sistema rodoviário do estado de Goiás em quilômetros.

Fonte: Elaborado pelos autores

\section{Considerações finais}

Há um claro padrão de distribuição espacial dos equipamentos do tipo pivô central no estado de Goiás. Este é regido por três fatores principais: pedologia (latossolos), relevo (declividade de até 6\%) e infraestrutura rodoviária (até $10 \mathrm{~km}$ de uma rodovia pavimentada). Esse conjunto de características agrupa cerca de $60 \%$ dos equipamentos.

O emprego da técnica de irrigação por pivôs centrais está consolidado em Goiás e tende a se expandir nos próximos anos, sendo esta uma expansão gradual e contínua, o que facilita ações de gestão a longo prazo. Regiões de grande densificação como Cristalina, Morrinhos e Jussara precisam ser observadas em contexto global nas ações de gestão.

Existe uma forte necessidade de analisar a demanda hídrica desses equipamentos, bem como as técnicas utilizadas e a relação consumo hídrico/produção no estado de Goiás. Esse esforço permitiria um melhor delineamento da capacidade de expansão e da vulnerabilidade dos recursos hídricos no território goiano, que são de suma importância para praticamente todo o território nacional.

A irrigação predomina em áreas de preço próximo à média. $\mathrm{O}$ preço da terra tende a indicar uma solução entre as diversas variáveis: topografia, fertilidade e infraestrutura. Ou seja, a irrigação não ocorre necessariamente nas terras com essa melhor solução. O mais provável é os produtores considerarem que as terras de preço "médio" apresentam 
as características necessárias, podendo utilizar a diferença de preço em relação às terras mais caras para intensificar o uso de tecnologia.

\section{Agradecimentos}

O autor Lindolfo Caetano Pereira Júnior agradece a Fundação de Amparo à Pesquisa do Estado de Goiás (FAPEG) pelo apoio financeiro realizado por meio da concessão da bolsa de mestrado proveniente da Chamada Pública 04/2015.

\section{Referências}

AGÊNCIA NACIONAL DE ÁGUAS (ANA); EMPRESA BRASILEIRA DE PESQUISA AGROPECUÁRIA (EMBRAPA). Levantamento da Agricultura Irrigada por Pivôs Centrais no Brasil - ano 2013. Brasília: ANA, 2013.

AGÊNCIA NACIONAL DE ENERGIA ELÉTRICA (ANEEL). Resolução Normativa 14/2010 - Condições gerais de fornecimento de energia elétrica, 2010.

ARISSANE, D. F. A dinâmica da fronteira agrícola em Goiás (1970-1985). 2006. Dissertação (Mestrado) - Faculdade de Ciências Humanas e Filosofia, Universidade Federal de Goiás, Goiânia, 2006.

BARRETTO, A. G. O. P. et al. Agricultural intensification in Brazil and its effects on land-use patterns: an analysis of the 1975-2006 period. Global ChangeBiology, v. 19, n. 6, p. 1804-1815, jun. 2013.

BEZERRA, L. M. C.; CLEPS JR., J. O desenvolvimento agrícola da região CentroOeste e as transformações no espaço agrário do estado de Goiás. Caminhos de Geografia, v. 2, n. 12, p. 29-49, 2004.

BRASIL. Lei $\mathrm{n}^{\circ}$ 9433, de 8 de janeiro de 1997. Institui a Política Nacional de Recursos Hídricos, cria o Sistema Nacional de Gerenciamento de Recursos Hídricos, regulamenta o inciso XIX do art. 21 da Constituição Federal, e altera o art. $1^{\circ}$ da Lei $\mathrm{n}^{\circ}$ 8.001, de 13 de março de 1990, que modificou a Lei $\mathrm{n}^{0} 7.990$, de 28 de dezembro de 1989. DOU, de 09/01/1997.

CARDOSO, M. R. D.; MARCUZZO, F. F. N.; BARROS, J. R. Classificação climática de Köpen-Geiger para o estado de Goiás e o Distrito Federal. Acta Geográfica, v. 8, n. 16, p. 40-55, 2014.

DARKO, R. O. et al. Irrigation, a productive tool for food security - a review. Acta Agricultura e Scandinavica, Section B - Soil \& Plant Science, v. 66, n. 3, p. 191206, 2 abr. 2016.

EITEN, G. Cerrado's vegetation. In: PINTO, M. N. (Org.). Cerrado: caracterização, ocupação e perspectivas. Brasília: Universidade Federal de Brasília (UNB), 1993. p. 17-73. 
FERREIRA, N. C.; MIZIARA, F.; RIBEIRO, N. V. Preço da terra em Goiás: pressupostos e modelos. Boletim Goiano de Geografia, v. 27, n. 1, p. 47-62, 2008.

FOSTER, S. et al. Proteção da qualidade da água subterrânea: um guia para empresas de abastecimento de água, órgãos municipais e agências ambientais. Washington, D.C.: Banco Internacional de Reconstrução e Desenvolvimento/ Banco Mundial, 2006.

INDEX MUNDI. Commodity prices. Disponível em: <http://www.indexmundi. com/commodities/>. Acesso em: 28 maio 2016.

INOCÊNCIO, M. E.; CALAÇA, M. Cerrado: fronteira da produção agrícola capitalista do século XX. In: XIX ENCONTRO NACIONAL DE GEOGRAFIA AGRÁRIA. Anais... São Paulo: 2009.

INSTITUTO MAURO BORGES DE ESTATÍSTICAS E ESTUDOS SOCIOECONÔMICOS (IMB). Estado de Goiás no contexto nacional - 2014. Goiânia: IMB, 2015.

INSTITUTO NACIONAL DE METEOROLOGIA (INMET). Normais climatológicas do Brasil 1961-1990. 1992. Disponível em: <http://www.inmet. gov.br/portal/index.php?r=clima/normaisClimatologicas $>$. Acesso em: 6 jun. 2016.

LÍVIA, M. DA C. S.; HORA, M. DE A. G. M. Conflito pelo uso da água na bacia hidrográfica do rio São Marcos: o estudo de caso da UHE Batalha. Engevista, v. 17, n. 2, p. 166-174, 2015.

MACEDO, F. C. Análise do preço da terra no estado de Goiás. Boletim Goiano de Geografia, v. 35, n. 1, p. 133-155, 2015.

MACHADO, R. B. et al. Estimativas de perda da área do Cerrado brasileiro. Brasília, DF: Conservação Internacional Brasil, 2007.

MARCUZZO, F.; FARIA, T. G.; PINTO FILHO, R. DE F. Chuvas no estado de Goiás: análise histórica e tendência futura. Revista ACTA Geográfica, v. 6, n. 12, p. 125-137, 2012.

MATSON, P. A. Agricultural Intensification and Ecosystem Properties. Science, v. 277, n. 5325, p. 504-509, 25 jul. 1997.

MIZIARA, F.; FERREIRA, N. C. Expansão da fronteira agrícola e evolução da ocupação e uso do espaço no estado de Goiás: subsídios à política ambiental. In: FERREIRA, L. G. (Org.). A encruzilhada socioambiental - biodiversidade, economia e sustentabilidade no Cerrado. Goiânia: Editora UFG, 2008. p. 112-126.

NASCIMENTO, M. A. L. S. Geomorfologia do estado de Goiás. Boletim Goiano de Geografia, v. 12, n. 1, p. 1-22, 1991.

ORGANIZAÇÃO DAS NAÇÕES UNIDAS PARA ALIMENTAÇÃO E AGRICULTURA (FAO). Global agriculture towards 2050. In: HIGH LEVEL EXPERT FORUM - HOW TO FEED THE WORLD 2050. Anais... Rome (Italy): FAO, 2009

. The state of the world's land and water resources for food and agriculture, managing systems at risk. Abingdon: SDGF, 2011. 
worldfoodsituation/csdb/en/>. Acesso em: 30 maio 2016.

PRADO, L. DE A.; MIZIARA, F.; FERREIRA, M. E. Expansão da fronteira agrícola e mudanças no uso do solo na região sul de Goiás: ação antrópica e características naturais do espaço. Boletim Goiano de Geografia, v. 32, n. 1, p. 151-165, 15 jun. 2012.

REZENDE, G. C. DE. Ocupação agrícola e estrutura agrária no Cerrado: o papel do preço da terra, dos recursos naturais e da tecnologia. Rio de Janeiro: Instituto de Pesquisa Econômica Aplicada (IPEA), 2002.

RODRIGUES, D. M. T.; MIZIARA, F. Expansão da fronteira agrícola: a intensificação da pecuária bovina no estado de Goiás. Pesquisa Agropecuária Tropical, v. 38, n. 1, p. 14-20, 2008.

SILVA, A. A.; MIZIARA, F. Avanço do setor sucroalcooleiro e expansão da fronteira agrícola em Goiás. Pesquisa Agropecuária Tropical, v. 41, n. 3, p. 399407, 6 jul. 2011.

SILVA, E. B. DA et al. A expansão da fronteira agrícola e a mudança de uso e cobertura da terra no centro-sul de Goiás, entre 1975 e 2010. Ateliê Geográfico, v. 7, n. 2, p. 116-138, 29 ago. 2013.

SILVA, F. ANTÔNIO M. DA et al. Variação espaço-temporal da disponibilidade hídrica climática no estado de Goiás. Pesquisa Agropecuária Brasileira, v. 33, n. 5, p. 605-612, 1998.

SPLINTER, W. E. Center-pivot irrigation. Scientific American, v. 234, n. 6, p. 9099, jun. 1976.

TAYLOR, R. G. Hydrology: when wells run dry. Nature, v. 516, p. 179-180, 2014. TEIXEIRA NETO, A. Pequena história da agropecuária goiana. Revista do Instituto Histórico e Geográfico de Goiás, v. 20, p. 19-29, 2009.

Lindolfo Caetano Pereira Junior - Graduado em Tecnologia em Geoprocessamento pelo Instituto Federal de Educação, Ciência e Tecnologia de Goiás (2010). Atualmente é analista em Infraestrutura de Transportes do Departamento Nacional de Infraestrutura de Transportes (DNIT) e mestre em Ciências Ambientais pela Universidade Federal de Goiás

Nilson Clementino Ferreira - Graduado em Engenharia Cartográfica pela Universidade Estadual Paulista Júlio de Mesquita Filho (1990), com mestrado em Engenharia de Transportes pela Universidade de São Paulo (1997) e doutorado em Ciências Ambientais pela Universidade Federal de Goiás (2006). Atualmente é professor da Escola de Engenharia Civil da Universidade Federal de Goiás.

Fausto Miziara - Graduado em Sociologia pela Universidade de Brasília (1996), com mestrado em Sociologia pela Universidade de Brasília (1989) e doutorado em Sociologia pela Universidade de Brasília (1995). Atualmente é professor titular da Universidade Federal de Goiás. 
Contribuições dos autores

Todos os autores ofereceram substanciais contribuições científicas e intelectuais ao estudo. As tarefas de concepção e design do estudo, preparação e redação do manuscrito, bem como, revisão crítica foram desenvolvidas em grupo. O autor Lindolfo Caetano Pereira Júnior ficou especialmente responsável pelo desenvolvimento teórico-conceitual e apoio no processamento dos dados; o segundo autor Nilson Clementino Ferreira, pela aquisição de dados e seu processamento interpretação e análise; e o terceiro Fausto Miziara, pelos procedimentos técnicos e apoio no desenvolvimento teórico-conceitual.

Recebido para publicação em 15 de fevereiro de 2017 Aceito para publicação em 27 de março de 2017 